\title{
Alcoolismo: Algumas Reflexões acerca do Imaginário de uma Doença
}

\author{
FERNANDO SÉRGIO DUMAS DOS SANTOS
}

\section{I}

Em um frio domingo de agosto, duas famílias amigas reúnem-se à mesa de um bar simples, em algum subúrbio carioca, para confraternizarem-se. Da cena fazem parte três senhoras de idades distintas: uma idosa, quase sem dentes e com ar cansado, trazendo no rosto as marcas indeléveis de uma vida dura de trabalho e necessidades; ao seu lado, uma outra, já na idade madura, com ares de matriarca, robusta e alegre, segurando um bebê que chora muito. De frente para elas uma jovem senhora sobriamente vestida, de aparência angelical, quase parva, de dona de casa feliz. Em companhia delas estão dois homens vestidos de maneira simples, porém bem-arrumados com a chamada "roupa de domingo". O primeiro usava boné, um bigodinho ralo, colarinho sem gravata e um cigarro enrolado pendente dos lábios; trazia uma expressão de felicidade estampada no rosto e era o marido da senhora robusta. À sua frente sentou-se o outro homem, trajando terno escuro e chapéu, e que também tinha um bigodinho ralo e um cigarro de enrolar pendente dos lábios como o seu companheiro; sua expressão era mais séria,

* Pesquisador da Casa de Oswaldo Cruz, chefe do Departamento de Arquivo e Documentação/ Casa de Oswaldo Cruz e mestrando em História Social na Unicamp. 
seu rosto mais fechado, denotando um temperamento, ao menos momentaneamente, menos expansivo.

O homem de boné estava sentado entre as duas senhoras mais novas a sua esposa e a do parceiro; entre esta e o marido estavam duas crianças de idades muito próximas e vestidas de forma semelhante: calças curtas, camisas de mangas compridas e bonés. Além deles, fazia parte da cena o dono do estabelecimento, um senhor de cabelos muito curtos, cortados à militar, colarinho e gravata, sem paletó, charuto no canto da boca e de atitudes solícitas, parecendo consciente do lucro que resultaria desse encontro. Este aspecto ganha relevância quando, ao olharmos atentamente para o proprietário, percebemos o vistoso anel, com uma enorme gema - aparentemente uma jóia de grande valor - , que ele usava. Sua solicitude, provavelmente advinha do fato de essas pessoas freqüentarem habitualmente o seu estabelecimento, contando-se entre os seus melhores fregueses.

Agora, o mais interessante em toda a cena é que todos os ocupantes da mesa bebiam vinho; até a criança de colo bebia do copo da mãe. O homem de terno enchia, novamente, o copo do menino ao seu lado, enquanto o outro garoto - sentado entre o primeiro e a esposa desse homem - bebia avidamente o seu copo de vinho. Além disso, o dono do bar vinha trazendo para a mesa mais três garrafas da bebida, como que para manter o clima alegre e festivo da reunião.

A cena descrita é uma charge que o cartunista Seth produziu, em 1931, para a coluna "Flagrantes Cariocas" do jornal $A$ Noite, e que recebeu o sugestivo título de "Alegrias de Domingo...". Nela o autor retrata algumas das representações construídas pelas classes dirigentes a respeito da educação, da família e do lazer das classes trabalhadoras, destacando a questão da alcoolização.

A ênfase dada a essa questão não é casual. Como já é sobejamente conhecido, desde o advento da República, e com o fim do trabalho escravo, grande parte da produção médica brasileira colocou-se a serviço da formação de um novo tipo de trabalhador: este deveria estar afinado com o assalariamento, com a industrialização e com a "modernidade" - tão cara aos historiadores de hoje. Os médicos brasileiros, longe de representarem interesses isolados, integravam-se a um movimento generalizado de normalização e disciplinamento da vida cotidiana.

1 A Noite, 10/8/1931. 
Na Europa, a constituição desse campo científico ganhou abrangência a partir do século XVIII, quando se delineara, para a medicina "quadros abertos e indefinidamente prolongáveis". ${ }^{2}$ Tornou-se então mais importante - no sentido de consolidar as práticas científicas - obter informações freqüentes, sistematizando-as de forma a permitir sua constante revisão, que cultivar a idéia de um saber médico totalizador e fechado em si.

No século XIX, com o avanço dos processos de urbanização e industrialização nos países europeus, o fenômeno de multidões circulando pelas principais cidades - grande parte delas morando e sobrevivendo nas ruas, vítimas que eram da miséria social reinante - sugeriu às elites dirigentes algumas formulações que possibilitassem a normalização de hábitos e atitudes considerados nocivos aos padrões éticos inerentes à sociedade capitalista industrial que se consolidava, a partir da introdução de uma noção nova e que dizia respeito ao corpo, às condições física, moral e biológica dos indivíduos: a saúde pública.

Ao longo dos séculos XVIII e XIX a concepção médico-científica de doença altera-se; essa noção ganha uma abrangência desmesurada à medida que se desenvolve uma prática médica essencialmente urbana, o que, naquela época, queria dizer social. Até a metade do século XVIII, a medicina havia reconhecido na doença uma natureza própria, e a essa natureza opunha a força de seus medicamentos. Não se colocara, ainda, um questionamento mais sofisticado a respeito de uma causalidade física do meio ambiente, por exemplo.

O doente figurava 'como um agente capaz de modificar as qualidades essenciais da doença, que, por sua vez, eram examinadas isoladamente e combinadas entre si, formando um mosaico do que deveria ser observado nos indivíduos enfermos. Havia uma identificação das características físicas do meio ambiente e das pessoas como participantes do processo de adoecimento; todavia, não se considerava como provável uma interferência de fatores tais como umidade do clima, condições da habitação, ou a contaminação da água no "movimento natural" da doença. ${ }^{3}$

A essa medicina, que Foucault denomina "classificatória" ou "das espécies", se opunha um conhecimento que relacionava todos os fatores passíveis de identificação pelos médicos. As condições do tempo e do clima, a topografia, a água e o homem, entre outros, eram apontados como causa-

2 M. Foucault, Microfísica do Poder" (3ª ed.), Rio de Janeiro, Ed. Graal, 1982, p. 80.

3 M. Foucault, $O$ Nascimento da Clínica $\left(3^{\text {a }}\right.$ ed.), Rio de Janeiro, Forense-Universitária, 1987, p. 30. 
dores de doenças. A noção de doença mudou, acompanhando o movimento da medicina que, naquele momento, se baseava em uma análise das constituições e das epidemias, isto é, ela admitia fatores externos - como os miasmas ou as fermentações - interferindo e provocando doenças, principalmente epidemias.

Essa prática possibilitou um esquadrinhamento da vida, marcado por uma complexa relação entre observações dos mais variados matizes e um quadro nosológico com abrangência suficiente para dar conta de toda a sociedade. O doente interessava ao médico enquanto resultado do cruzamento de diversas informações que se ampliavam indefinidamente à medida que se complexificava o espaço social. A civilização burguesa trouxe consigo doenças específicas de seu tempo, características das aglomerações nas cidades e do trabalho fabril; constatou-se, a partir de então, um sem-número de doenças novas, que exigiam modernas profilaxias.

Naquele momento, engendrava-se uma outra noção de doença: a doença social. Por volta de 1850 , esse conceito se encontrava amplamente difundido, abrangendo moléstias derivadas do convívio social, como a tuberculose, a sífilis, a loucura e o alcoolismo. Doenças nitidamente vinculadas ao desenvolvimento do modo de produção capitalista e associadas, virtualmente, às populações pobres, à miséria urbana e a valores morais constitutivos da ética do trabalho.

Antes de nos atermos a esse ponto, porém, vale ressaltar a total compatibilidade entre o ideal constitutivo da sociedade burguesa, visivel principalmente no papel regenerador que as disciplinas desempenham em relação aos indivíduos, e a medicina social, fruto das preocupações das classes dirigentes com o crescimento da população urbana e da necessidade de garantir a manutenção e a reprodução da força de trabalho que movimenta $o$ capitalismo. Não só as disciplinas estavam presentes nos arquétipos da medicina social, com o esquadrinhamento quase total do cotidiano, mas a vigilância e a política eram parte dessa concepção de medicina científica do século XIX.

Os micropoderes, aos quais Michel Foucault atribui uma importância expressiva no mundo das relações capitalistas, constituem, ao mesmo tempo, o objeto e a essência dessa medicina globalizante, que, todavia, busca nas especialidades, nas observações diversificadas e sistemáticas o conteúdo dos seus saberes.

Não é por acaso que na sociedade burguesa instituições nitidamente disciplinares são tão parecidas: o hospital, o quartel e a escola, por exemplo, têm constituições consoantes com o ideal burguês de liberdade com ordem, 
estando organizados de forma a fazer valer um tratamento diferenciado e segmentado, segundo as hierarquias da sociedade.

A participação de médicos no quadro jurídico vigente era formalizada por meio da medicina legal, que requeria laudos e pareceres médicos considerados legítimos para definir determinadas questões jurídicas. Informalmente, eram os pressupostos das ciências biomédicas que fundamentavam o cotidiano da sociedade, abarcando, por exemplo, setores como a administração pública, a arquitetura e a família.

Segundo Foucault, "o lugar natural da doença é o lugar natural da vida - a família"; ${ }^{4}$ isto, todavia, vale para a medicina classificatória, introspectiva, que era praticada até o século XVIII. A família burguesa é a célula da sociedade, estando, portanto, sujeita às determinações que regem esta última; resulta daí ser a família (o lar), nessa sociedade, o espaço primeiro da saúde, que, por sua vez, é a condição para o pleno rendimento produtivo do indivíduo. A produção médica desse período ficou cada vez mais engajada no processo de montagem política de uma ordem burguesa, fornecendo dados e valores para a codificação jurídica da sociedade.

No limiar do século XX, o Brasil já queria se considerar um país com face urbana; porém sua economia ainda se baseava nas monoculturas exportadoras, sendo o café o seu principal produto, seguido da borracha e do açúcar. As indústrias se localizavam, principalmente, no Rio de Janeiro, em São Paulo e em Juiz de Fora, e a força de trabalho compunha-se basicamente de ex-escravos e de imigrantes.

Desde o último quartel do século XIX, explicitavam-se articulações que tendiam a generalizar as especificidades urbanas para o resto do País, já que era no contexto da cidade que se realizava o projeto de modernização burguesa tão desejado pelas elites brasileiras. Com esse propósito, adaptou-se às nossas condições todo o instrumental normativo e disciplinador produzido nas sociedades européia e norte-americana ao longo desse século.

A formação de um cidadão brasileiro e de um novo trabalhador, vinculados a uma lógica capitalista, colocou-se como questão prioritária. Em conseqüência, foi desenvolvido todo um aparato jurídico e moral que viria a legitimar algumas medidas de impacto imediato e outras de longo prazo, que buscavam atingir diretamente o cotidiano da população, modificando noções de família, trabalho e lazer, entre outros hábitos. Porém, um projeto elaborado de cima para baixo gera resistências em todos os níveis, além do que

4 Idem, p. 18. Ver, a respeito, o cap. I. 
não havia (como não há, nem nunca houve) homogeneidade no âmbito das diferentes classes sociais. Portanto, em todos os niveis encontram-se distintas versões para acontecimentos idênticos, o que significa que existem diferentes representações sobre os mesmos temas no imaginário dessa sociedade, vinculadas tanto à condição social do indivíduo, como à sua própria personalidade. Parece-me claro, no entanto, que algumas imagens comuns podem ser extraídas de diversas fontes históricas, compondo um mosaico de significados e interpretações vigentes na nossa sociedade.

\section{II}

A família e o trabalho são dois temas abordados pelo cartunista Seth na charge anteriormente descrita. Todavia, o objeto central da mesma é uma "doença social": o alcoolismo, ou a disseminação entre as classes populares do hábito de consumir o "álcool potável" — também chamado de "verdadeiro representante do gênio do mal". ${ }^{5} \mathrm{O}$ alcoolismo foi objeto de teses nas Faculdades de Medicina a partir da segunda metade do século passado, aparecendo pela primeira vez em 1854 e voltando com certa recorrência até 1920. Nas primeiras décadas deste século o antialcoolismo é tema, também, de reiteradas campanhas, tanto na imprensa como em diversas instituições.

Adjetivos como "demônio da humanidade", "diabólico" e "gênio da degeneração", entre outros, fizeram parte do arsenal retórico utilizado por setores mais radicais, em uma verdadeira cruzada empreendida com a intenção de retirar do cotidiano da população brasileira o costume de consumir o "parati". É interessante, porém, a constatação de uma séria divergência nas classes dominantes quanto a essa questão. Evaristo de Moraes, comentando a respeito de uma sobretaxação das bebidas alcoólicas no Brasil, afirma que "pouco se consegue, devido à intervenção dos produtores de álcool, que, por meios nem sempre confessáveis, dominam o Congresso". 6

O grande alvo das propostas antialcoólicas no início de século foi, realmente, a população pobre. A vinculação estreita entre miséria social e alcoolização dominava o pensamento de todos os setores, inclusive das clas-

5 A expressão foi utilizada por Belisário Penna, em entrevista ao jornal $O \dot{O}$ Globo, por ocasião do carnaval de 1925. O original datilografado encontra-se no Arquivo Belisário Penna. COC/Fiocruz.

6 E. de Moraes, "O Alcoolismo", in E. de Moraes, Ensaios de Patologia Social, Rio de Janeiro, Ed. Leite Ribeiro, 1921, p. 90. 
ses trabalhadoras que, apesar de não abdicarem do botequim como espaço de lazer, ${ }^{7}$ agiam de forma a legitimar a condenação do hábito e do espaço, incorporando ao senso comum as noções burguesas a respeito da questão.

Alguns setores dirigentes empenhados nas campanhas antialcoólicas, porém, não propunham nenhum tipo de atuação específica contra as classes populares. Ao contrário, Belisário Penna, em conferência realizada a convite da recém-criada Liga Nacional contra o Alcoolismo, em 27 de junho de 1921, afirmou que o vício alcoólico ocorre, também, "entre os dirigentes, os poderosos e os ricos" e "entre as classes intermediárias", resultando, no primeiro caso, "na dissolução de costumes, no fausto, na luxúria, no egoísmo, na violência, na extorsão, no egotismo"; nas classes médias, o autor identifica que o consumo de bebidas alcoólicas "resulta na subserviência, na bajulação, no servilismo, no latrocínio, na fraude, na falsificação e na burla". 8

O sanitarista considerava necessário que a sociedade civil se organizasse para "o combate sistemático, pertinaz, violento até, contra um dos elementos destruidores da saúde e o mais perverso da inteligência e dos atributọs morais do homem". ${ }^{9}$ Mesmo impregnado de uma visão eugênica da sociedade - procurando a raça ideal e o fim das "degenerescências da espécie" - e com um discurso pautado basicamente pelo aspecto moral, ele expressava, em linhas gerais, o pensamento de grande parte da população sobre o consumo exagerado de bebidas alcoólicas.

A ênfase de Belisário Penna na abstinência como fator de longevidade, de produtividade e de saúde do homem é, talvez, mais radical que a média; todavia, a medida era considerada necessária também por Evaristo de Moraes, um importante advogado das causas operárias do início deste século e homem vinculado aos princípios do laissez-faire europeu. O radicalismo da campanha de Belisário Penna pelo "saneamento do Brasil" 10 era fruto de uma crítica às posições políticas das elites brasileiras, que ele chamava "politicalha"."11

Segundo essa linha de pensamento, o trabalho significa o único elemento regenerador da raça humana. O homem e o trabalhador formam uma única e indivisível figura geradora de riqueza e de virtudes: "ao homem, tocado

7 Sobre o assunto, ver S. Chalhoub, Trabalho, Lar e Botequim, São Paulo, Ed. Brasiliense, 1986.

8 B. Penna, O Demônio da Humanidade, Rio de Janeiro, Casa Publicadora Batista, 1921, p. 9.

9 Idem, p. 1.

10 B. Penna, O Saneamento do Brasil, Rio de Janeiro, Typ. Revista dos Tribunais, 1918.

11 A expressão é muito utilizada por Belisário Penna em $O$ Saneamento do Brasil..., op. cit. 
pela centelha divina, foram concedidas faculdades superiores". ${ }^{12} \mathrm{Um}$ dos autores citados por Belisário Penna, o francês Gasset, comparava o efeito causado pelo consumo de bebidas alcoólicas com a senilidade, levando esta comparação para o campo das relações de produção, onde ele verificou a existência de uma "esclerose que invade a economia". ${ }^{13} \mathrm{O}$ médico brasileiro compartilhava com o teórico europeu dessa formulação, que compreendia a sociedade enquanto um organismo funcional, no qual a bebida alcoólica representaria um agente depredador de suas funções.

Para esses teóricos, tornava-se imprescindível que as elites brasileiras finalizassem o processo de normalização da sociedade então em curso, concretizando, em um aparato jurídico e moral, os códigos que vinham sendo estabelecidos. Só assim o País poderia desenvolver plenamente o seu potencial produtivo e alinhar-se, soberbamente, ao lado das maiores potências do mundo capitalista.

Como Foucault ressalta, "relacionar os atos, os desempenhos, os comportamentos singulares a um conjunto, que é ao mesmo tempo campo de comparação, espaço de diferenciação e princípio de uma regra a seguir", é uma das operações observadas "no regime do poder disciplinar". ${ }^{14}$ Nesse sentido, a crítica aos pares fazia parte de uma contabilização eugênica dessa relação, não tendo características que objetivassem á subversão do modelo de hierarquia social. Citando Magnan, Belisário Penna definia como "degenerados superiores" aqueles "inteligentes, mas desequilibrados":

“[...]um hereditário [alcoólico] pode ser um sábio, um magistrado distinto, um matemático eminente, um político sagaz, um administrador hábil, e apresentar sob o ponto de vista da moral, defeitos profundos, caprichos estranhos, desvios de conduta surpreendentes, e como o lado moral, os sentimentos e as inclinações são a base de nossas determinações, segue-se que as faculdades brilhantes são postas ao serviço de uma causa má, isto é, de instintos, de apetites, de sentimentos mórbidos, que, graças ao desfalecimento da vontade, impelem aos atos mais extravagantes e por vezes os mais perigosos". 15

Uma conduta ilibada das classes dirigentes tornava-se condição primeira para alcançar o espírito civilizado do capitalismo. Não vendo esses exemplos, as classes menos educadas se entregariam aos seus instintos, daí resultando o vício, a miséria e o fatalismo. À negatividade atribuída aos instintos,

12 B. Penna, O Demônio da Humanidade..., op. cit., p. 2.

13 Expressão cunhada pelo estudioso francês e citada por Belisário Penna em $O$ Demônio da Humanidade..., op. cit., p. 8.

14 M. Foucault, Vigiar e Punir, Petrópolis, Ed. Vozes, 1977, p. 163.

15 B. Penna, O Demônio da Humanidade..., op. cit, p. 9. 
aos apetites e aos sentimentos somava-se o desejo de controlar, definir e entender a complexidade das relações sociais nessa sociedade moderna, definida pelo mercado e pelas relações de produção. A população pobre emergiu, então, como o principal personagem dessa trama: ora no papel de vítima dos desmandos da "politicalha" e, quiçá, de alguns "degenerados superiores", ora como ativos opositores, subversivos potenciais da ordem burguesa, ou, ainda, como povo - os que assistiam bestializados às transformações. ${ }^{16}$

Os "alcoólatras" identificados nas falas oficiais são, via de regra, oriundos dessas classes. Havia um reconhecimento latente, principalmente por parte dos que estudavam as "doenças sociais", da relação entre assalariamento da força de trabalho e o que eles definiam por "miséria social", a qual só era atenuada pelo "bom trabalhador", uma imagem criada a partir das auto-representações burguesas e apresentada à população como o modelo ideal. O alcoolismo e a miséria eram interpretados segundo uma dialética muito original:

“[...]se é verdade que grande número de alcoólicos foram, outrora, bons operários (ganhando fartamente com que sustentar-se e às suas famílias) e impelidos, pouco a pouco (fosse por maus exemplos, fosse por circunstâncias desgraçadas), para a trilha funesta, só devem a seu vício a penúria em que se encontram; não menos certo é que o pauperismo, com todas as suas conseqüências - alimentação insuficiente, habitação malsã, desordenş e sujidade do lar doméstico - conduz, de maneira quase irresistível, os homens para as casas de bebidas, onde eles encontram, momentaneamente, o esquecimento dos seus males e das suas misérias". 17

A imbricação entre a "doença" e a condição social não se resume a uma relação de causa e efeito; todavia, esta era dada como recorrente por Evaristo de Moraes, que afirmava que o abuso de bebidas alcoólicas é maior nas classes pobres, "e, em especial, no seio do operariado". ${ }^{18}$ Os trabalhadores, efetivamente, confirmavam sua condição de preocupação maior das elites, que indicavam como caminho para o seu "adestramento" a educação. A falta de educação das populações pobres era apontada como favorecedora da “criminalidade de origem alcoólica, porque, entre elas, não se opõe à ação do álcool a reação da cultura, da educação moral, da tradição familiar e de outros freios inibitórios". ${ }^{19}$ Ao mesmo tempo, a educação representava um

16 Ver J. M. de Carvalho, Os Bestializados. O Rio de Janeiro e a República que Não Foi, São Paulo, Cia. das Letras, 1987.

17 A. Jacquet apud E. de Moraes, "O Alcoolismo...”, op. cit., pp. 97-8.

18 Idem, p. 103.

19 Ibidem. 
dos principais símbolos da ascensão social burguesa, significando, ainda hoje, uma regra a ser seguida para a normalização dos padrões comportamentais.

Por essa época, havia uma opinião corrente entre a intelectualidade e não só a brasileira - de que

"[...]nas classes superiores, a ação do álcool se revela menos intensamente, em virtude da reação que the é oposta pela cultura, pela educação, pelo meio coletivo já sensível aos escândalos do alcoolismo. $O$ álcool não é, entre as aludidas classes, a causa preponderante da sua criminalidade, embora concorra para ela em grande parte". 20

Estatísticas de toda sorte foram elaboradas com o intuito de preservar a burguesia desses "escândalos". Despossuídos, como Ada Jurke, que era acusada de ser bêbada, ladra e vagabunda, ${ }^{21}$ estavam sujeitos a uma total devassa de sua descendência por serem considerados anormais; seus crimes - a bebida e a vagabundagem - representavam, senão uma possibilidade de dissolução, ao menos uma forte rejeição à ordem capitalista. Tanto que Evaristo de Moraes não tinha dúvidas em reconhecer como válido o uso da força contra aquelas pessoas consideradas alcoólatras, "justificando-se, em face dos princípios do liberalismo e da democracia, a intervenção defensiva do Estado, coagindo o bêbado enfermo a se tratar convenientemente". ${ }^{22}$ A sensação de ameaça que pairava sobre o bêbado fazia lembrar o horror à lepra na Europa do final da Idade Média. Só que agora o estigma se estabelecia a partir do ponto de vista da moral burguesa vinculada à ética do trabalho. A atuação da Igreja é fundamental nos dois momentos, todavia a moral do pecado não existe mais, o estigma mudou de forma.

A intervenção do Estado na sociedade era, em sua prática, muito mais ostensiva do que defensiva e a forte presença policial na cidade é um indicador disso. à polícia cabia acompanhar, no cotidiano, as questões sociais que se relacionassem às classes pobres urbanas, utilizando-se do instrumental médico-jurídico para orientar suas ações. A prisão e o hospital — o hospício também é um hospital - eram as instituições adequadas para tratar os casos mais graves.

No final da década de 1910 surge, no cenário político brasileiro, mais uma tentativa de copiar os movimentos oriundos da sociedade norte-americana. Em 1919, foi editada nos Estados Unidos a famigerada "lei seca", que proibiu o fabrico, o transporte e a comercialização de qualquer bebida alcoó-

20 Idem, p. 108.

21 B. Penna, O.Demônio da Humanidade..., op. cit., p. 3.

22 Idem, p. 109. 
lica em todo o país. O governo norte-americano foi exaltado, em sua coragem e firmeza, pelos que pleiteavam mais rigor do governo brasileiro a esse respeito; aquele era o comportamento a ser seguido.

O sentido de tal lei repousava na articulação entre um projeto de Estado, que visava o estabelecimento de uma economia pragmática, e um projeto dos setores de ponta da indústria norte-americana, capitaneados por Henry Ford, que visava aperfeiçoar os métodos de trabalho capitalistas. A formação de um "novo tipo de trabalhador conforme uma indústria fordizada exigia", ${ }^{23}$ pressupunha novos hábitos e novas representações dos sinais vitais do mundo. A moral protestante era o instrumento ideal para essas transformações, já que sua verve religiosa encontrava eco no imaginário popular nos Estados Unidos e na Europa, e as práticas de vida adotadas pelos seguidores desses cultos se adequavam sobremaneira aos objetivos das elites capitalistas.

Lá, o proibicionismo colocou-se como uma condição para a modernização das relações de produção; aqui, ainda se buscava consolidar os investimentos no setor industrial. E, na produção desse setor, à época, as bebidas alcoólicas tinham relativa expressão. Segundo Belisário Penna, a União arrecadou, em 1921, com impostos sobre a fabricação e o comércio de bebidas alcoólicas, cerca de $40 \mathrm{mil}$ contos/ano; essa renda foi revertida para o Serviço de Profilaxia Rural. O mesmo autor divulgou os números encontrados pelo médico Hermeto Lima para o consumo diário de bebidas alcoólicas no Rio de Janeiro: em 1914, 229.264 litros, sendo 71.580 litros de cachaça.

Por isso, apesar das insistentes campanhas pela proibição das bebidas alcoólicas, realizadas por setores das elites, prevaleceram os interesses dos produtores. A discussão fica evidente quando Evaristo de Moraes afirma que médicos, juristas, políticos, sanitaristas como "Cunha Cruz, Medeiros e Albuquerque, Domingos Jaguaribe, Lopes Trovão, Correia de Freitas, Henrique Lagden, Souza Lima, Moncorvo Filho, Hermeto Lima, Juvenal Lamartine, não conseguiram interessar as classes dirigentes". ${ }^{24}$ Mas a polícia cumpria o seu papel, representando o Estado brasileiro nas questões sociais.

Os graves problemas de desigualdade social estavam na gênese da "doença". Reconhecia-se o nexo entre a baixa qualidade de vida das classes populares e a maior incidência de alcoolismo nesses segmentos sociais. As

23 A. Gramsci, Maquiavel, a Política e o Estado Moderno, Rio de Janeiro, Ed. Civilização Brasileira, 1984, p. 376.

24 E. de Moraes, “O Alcoolismo...," op. cit., p. 93. 
condições de trabalho, de habitação e de saúde eram apresentadas como fatores causadores do problema. Mesmo sendo amplamente difundida no Brasil, a relação miséria social alcoolismo não resultou em medidas práticas por parte do governo, além da atuação policial. Sendo assim, restava como possibilidade de resistir à "enfermidade", segundo alguns "antialcoolistas", a educação familiar de tipo burguês, a qual não tinha, ainda, grande repercussão nas classes pobres.

A família surgia, então, como responsável pela temperança dos instintos. A mesma noção de moral que embasou as teorias fordistas impregnava alguns setores das classes dominantes brasileiras. Mas, aqui, havia outros elementos contrapondo-se a esses conceitos. Em primeiro lugar, a cultura católica brasileira era (e é) muito mais permissiva, no tocante a questões como o trabalho produtivo capitalista ou o consumo de bebidas alcoólicas, do que a tradição protestante americana. Além disso, as religiões de origem africana, muito difundidas entre a massa trabalhadora, também não colocavam obstáculos quanto a essas questões

O modus vivendi da maioria da população brasileira era um entrave aos projetos de modernização da sociedade engendrados pela burguesia. Seus hábitos cotidianos, seus métodos de trabalho, a própria relação entre o povo e o poder público não estavam de acordo com aquela racionalidade, voltada para a produtividade da força de trabalho e o aumento da produção. No caso do costume de consumir bebidas alcoólicas, todavia, a tentativa de controle por parte do Estado não era um privilégio brasileiro; ao contrário, disseminava-se por todo o Ocidente, acompanhando a "medicalização" e o esquadrinhamento científico e tecnológico da sociedade.

Existia um confronto entre a "racionalidade colonial dos nossos hábitos" e o "fascínio temeroso de nossas elites diante do moderno das idéias européias". ${ }^{25}$ Por volta da metade do século XIX, emergia, do cruzamento dessas duas tendências gerais, a família como elemento fundamental para viabilizar a ordem burguesa. A família celular passou a figurar, principalmente nos centros urbanos, como um elemento da saúde, da higiene, da educação, da assepsia desse modelo social, em oposição à promiscuidade, à doença e à desordem da racionalidade colonial.

Por outro lado, a desestruturação da família aparecia como resultado de perversões e degenerações motivadas pela miséria, pelos vícios, pelas doenças ou por antigos hábitos. A ação da bebida alcoólica na destruição de

25 K. Muricy, A Razão Cética, São Paulo, Cia. das Letras, 1988, p. 36. 
lares e desagregação da família foi sempre enfatizada pelos que combatiam o seu uso. Na qualidade de chefe da família, o homem era o responsável pelo suprimento e estabilidade econômica do lar; à mulher cabia cuidar da consolidação emocional e administrativa da família. A educação, nesse caso, era uma tarefa feminina, dela fazendo parte as questões morais.

A mulher desempenhava, então, um papel de destaque na manutenção do equilíbrio social. Era no lar, e não na rua, que deviam se desenvolver as principais e mais fortes relações pessoais. O lar, comandado pela mulher, tornou-se o centro irradiador dos modos, da educação, da ética burguesa. A noção de mulher "rainha do lar" era muito peculiar, porque, politicamente, a figura feminina era engrandecida, ela ganhava o acesso à sala e à rua. Mas era dela, efetivamente, que devia partir o controle, a temperança dos hábitos, dos instintos e dos apetites.

O alcoolismo simbolizava um mal degenerador da família. Jaquet, por exemplo, ao analisar os números da "doença", observa que "o lar doméstico devastado, os sofrimentos e as lágrimas da mãe de família, os filhos abandonados, não figuram em tais estatísticas. No entanto, é, sobretudo, ali que se deve procurar a origem de todo o mal que sofre a sociedade". ${ }^{26}$ A mulher era uma das principais vítimas do alcoolismo. A violência contra ela, perpetrada em estado de embriaguez pelos maridos, causava não só a dissolução familiar, como também os crimes passionais. Em um desses casos, o jornalista João Pereira Barreto, redator dos debates da Câmara Federal, assassinou, em casa, sua esposa, no dia 2 de dezembro de 1912, alegando posteriormente estar fora do seu juízo, pois bebera muito e participara de uma sessão de hipnotismo na Confeitaria Paschoal, na rua São José, no centro do Rio de Janeiro. ${ }^{27}$

Em muitos lugares a reação das mulheres, por intermédio dos movimentos feministas, articulou-se às campanhas antialcoólicas. Segundo Evaristo de Moraes, as mulheres atuaram decisivamente nos Estados Unidos, para a aprovação da lei seca, e na Nova Zelândia. "Num e noutro casos o que se averiguou foi a valiosíssima e tenacíssima cooperação da mulher, quer agindo particularmente nas associações de temperança, quer votando nos plebiscitos e nas corporações legislativas": ${ }^{28}$ Também na Inglaterra mereceu

26 Louis Jacquet apud Cunha Cruz, O Problema do Alcoolismo no Brasil, Rio de Janeiro, Typ. do Jornal do Comércio, 1906, p. 7.

27 F. Esposel e E. Lopes, Uma Pericia Médico-Legal, Rio de Janeiro, Hospital Nacional de Alienados, 1914

28 E. de Moraes, "Feminismo e Anti-Alcoolismo", Jornal do Brasil, 22/3/1923. 
destaque a participação feminina nessas atividades. É interessante notar que todos os três países citados pelo autor têm, em suas culturas, sólidas raízes protestantes.

No Brasil, ao contrário, o Dr. Cunha Cruz assinalou que "é digno de atenção o número que indica a proporção de mulheres com perturbações mentais, devidas ao alcoolismo, em nosso hospício e colônias. Essa proporção é tão grande que difícil é encontrar igual em estatísticas, mesmo nos países mais alcoolizados". ${ }^{29}$

A idealização da mulher como utopia da pureza, da liberdade e da esperança ${ }^{30}$ impunha a ela um duplo movimento, de exteriorização e interiorização, operado pela noção de família. "De um lado, o público: as recepções, os saraus, a freqüência aos bailes e teatros; de outro, o privado: a organização da casa visando à criação de um ambiente de aconchego e conforto, reservado à convivência familiar e ao lazer". ${ }^{31}$ Essa dicotomia entre o público e o privado estabelece a diferença entre um "modo de beber social", educado, sofisticado e, principalmente, bem relacionado, e a "embriaguez pública", figura jurídica que legitimava a repressão policial aos freqüentadores dos botequins, biroscas, tavernas e quiosques das cidades.

Mas o olhar "medicalizado" encontra o alcoolismo disseminado por toda a sociedade, atacando e destruindo sua célula principal: a família. Tornavam-se necessárias medidas enérgicas para coibir esses abusos.

"Filho, marido, irmāo, julga-se com maior ou menor direito de sentar-se à mesa comum, de dormir sob o mesmo teto, de gozar as regalias inerentes à sua posição familiar, praticando, entretanto, toda sorte de desatinos, não contribuindo para a mantença da casa, gastando sem conta, impondo-se pelo terror, procedendo obscenamente, dando os mais deprimentes e escandalosos espetáculos". 32

Quando não levava a bom termo a responsabilidade que lhe foi confiada, o homem perdia a condição moral de chefiar a casa; a mulher emergia, então, como vítima dessa situação. Se verificarmos na citação acima, as mulheres (esposa, filha e irmã) são, implicitamente, as ofendidas.

Os populares, por sua vez, insistiam nas tradições culturais que lhes eram caras - talvez nem mesmo conseguissem organizar o seu dia-a-dia de outra maneira. Os dados referentes às mulheres dessas classes reforçam essa

29 Cunha Cruz, O Problema do..., op. cit, p. 14.

30 Ver o instigante artigo de E. J. Hobsbawm, "Homens e Mulheres: Imagens da Esquerda", in E. J. Hobsbawm, Mundos do Trabalho ( $2^{\mathrm{a}}$ ed.), Rio de Janeiro, Paz e Terra, 1988.

31 K. Muricy, A Razão Cética..., op. cit., p. 111.

32 E. de Moraes, "O Alcoolismo...", op. cit., p. 125 
evidência, apontando para um modo de vida bastante difundido. O hábito de consumir "parati", compartilhado por essas pessoas, foi identificado por vários autores da época. Evaristo de Moraes observa que, no Brasil, "a cachaça é hábito enraizado entre os escravos e as populações mais pobres". 33 A abrangência deste costume compreendia as mulheres dessas classes sociais, tendo a cachaça sido incluída na ração diária que era servida aos escravos. Ainda hoje, em determinadas ocupações - como a dos bóias-frias, por exemplo - é comum o consumo de aguardente como complemento da alimentação diária. Significativo, a esse respeito, é o depoimento de Belisário Penna:

“[...]a importação das bebidas alcoólicas e a sua fabricação nacional hoje são conseqüências da imigração de povos que trouxeram o hábito e a indústria, com exceção talvez da cachaça, lembrança das fazendas de açúcar, mas ela também criminosamente introduzida no meio do povo trabalhador que originalmente não a conhecia". 34

A formulação eugênica que o autor emprestava às suas idéias, levava-o a visualizar uma "raça brasileira" e um "povo brasileiro" desvinculados de outras influências culturais. A alma brasileira que ele perseguia tinha sua gênese no território nacional, surgindo pura e casta na essência de cada indivíduo. O "povo trabalhador", pela sua deseducação ou, simplesmente, por não ter levada em conta sua voz política, era considerado vítima dos desmandos e descalabros de uma classe dirigente sem virtudes, viciada e corrupta, despreparada para o exercício do poder.

A mitificação que Belisário Penna fazia das classes trabalhadoras não permitiu que ele lhes atribuísse uma essência profana; assim o hábito de consumir bebidas alcoólicas e as respectivas indústrias teriam vindo com a imigração. E mesmo a cachaça, reconhecidamente vinculada ao trabalho escravo, aparecia como mais uma "ação criminosa" de uma elite atrasada e argentária. As tradições culturais das classes populares, estreitamente ligadas aos rituais religiosos africanos, são desconsideradas. Para o autor, a origem dessa gente está no Brasil, ou melhor, essa procedência se confunde com o próprio nascimento no Brasil.

Ironicamente, o próprio Belisário constata que “[...]em qualquer venda ou taxa dos povoados, das fazendas e das estradas, estará [...] a um canto sempre repleto, o quinto de cachaça, pintado em geral de verde e amarelo[...]". ${ }^{35}$ A nação identifica-se com a bebida e por ela é identificada. O

33 E. de Moraes, "O Alcoolismo...", op. cit., p. 92.

34 B. Penna, O Combate ao Alcoolismo, Arquivo Belisário Penna, COC/Fiocruz, s/d, datilo.

35 B. Penna, O Demônio da Humanidade..., op. cit., p. 11. 
imaginário social foi objeto de uma série de intervenções, com a criação de novos significados e de alguns símbolos, no sentido de coagir a maior parte da população (as classes populares) a incorporar as representações difundidas pelas elites, inclusive no que tangia ao alcoolismo. Entre os novos significados atribuídos a antigos significantes ${ }^{36}$ destaca-se a reinvenção da figura mística do monstro. Ao colocar o alcoolismo no processo de gênese de um quadro tão aterrador, a medicina científica reinventou o monstro, plasmando-o ao homem e às degenerescências que lhe eram atribuídas por conta da "doença".

Só que o monstro de agora não é mais um enorme e furioso dragão, nem uma sensual sereia; ele está muito mais próximo do monstro que representava o leproso na Idade Média, definido pela deformação física do ser humano. O monstro moderno foi forjado a partir das necessidades impostas por uma sociedade que privilegia o lucro, as relações de produção, que se sustenta em uma moralidade cristã voltada para seus próprios interesses e atrelada às modernas práticas científicas. A deformação não aparece mais no corpo do doente, nem é compreendida como um castigo de Deus; a deformação está no espírito, na vontade, e retira das pessoas a sua humanidade que lhes é dada pela sua inserção no sistema produtivo. O diabo continua presente, como na Idade Média, responsabilizando-se, agora, pela propagação desse mal.

"A lei de ferro da herança, que transmite aos filhos as qualidades e os defeitos dos pais, pesa brutalmente sobre a progênie dos bêbados. Os filhos de alcoólicos serão alcoólicos de diversos tipos, dentre eles: homicidas, suicidas, epiléticos, histéricos, neurastênicos; dipsomaníacos, alienados". 37

Segundo Belisário Penna, Morel apontou, a partir dessa teoria da hereditariedade alcoólica, a possibilidade de "extinção provável da raça na quarta geração de alcoolizados", 38

O fruto monstruoso dessas taras é, conforme os especialistas da época, gerado durante a embriaguez dos pais - ou de apenas um dos parceiros "já que o álcool impregna o espermatozóide e o óvulo". 39 A sexualidade era

36 Sobre os significados e os significantes, ver C. Castoriadis, A Instituição Imaginária da Sociedade, Rio de Janeiro, Paz e Terra, 1982, esp. cap. III, “A Instituição e o Imaginário: Primeira Abordagem", no qual o autor desenvolve esses conceitos.

37 F. Cleto, O Alcoolismo e suas Conseqüências, Tese de Doutorado, Faculdade de Medicina da. Bahia, 1907.

38 B. Penna, O Demônio da Humanidade..., op. cit, p. 4.

39 A. L. de Souza, Causas e Tratamento de Alcoolismo, Tese de Doutorado, Faculdade de Medicina de Porto Alegre, 1904. 
objeto, ao mesmo tempo, de uma reeducação (ou recriação) visando consolidar a lógica capitalista. É inevitável relacionar esses dois níveis do movimento.

"Os instintos sexuais são os que sofreram a maior repressão da sociedade em desenvolvimento; a sua 'regulamentação', em virtude das contradições que gera e das pressões que lhe são atribuídas, parece mais 'inatural'; assim, são mais freqüentes neste campo os apelos à natureza". 40

O álcool e o sexo representavam os caminhos e os objetivos da natureza irracional que se buscava apagar no homem. Para Belisário Penna, a relação entre o alcoolismo e a sífilis era intrínseca. Eles se alimentavam mutuamente, degenerando a raça e povoando os hospitais, hospícios, prisões e cemitérios. A maior incidência dos dois "flagelos" nas classes mais pobres significava para uns uma predisposição física ou social, para outros o descaso com que essa população era tratada. De qualquer forma, um novo padrão de valores vinha sendo apresentado, em oposição às tradicionais formas populares. Com maior ou menor empenho e rigidez, as elites dirigentes disseminavam um ideal higiênico que abarcava todos os momentos da vida, inclusive a morte.

Simbolicamente, a higiene significava um elemento novo, inventado pela racionalidade científica e amparado na mística da religião. A intervenção deste signo no campo sexual ressalta um dos paradigmas comportamentais difundidos pela Igreja. O prazer sexual deixou de ser pecado e passou a ser doença; da mesma forma, o hábito de embriagar-se, que na Idade Média era um problema para os inquisidores, "epidemiologizou-se".

A conjunção de alcoolismo e sífilis tendia, na perspectiva da eugenia, a criar uma espécie completamente degenerada, desvirtuada moralmente e irremediavelmente doente. As relações sexuais entre bêbados e sifilíticos significavam a perpetuação do mal nas gerações subseqüentes. Belisário Penna chega a afirmar, em um artigo intitulado "Sífilis e Alcoolismo", que, caso fosse feito

"um inquérito rigorosamente científico, verificar-se-ia que, na sua maioria, as nossas escolas eram freqüentadas por crianças anormais; de sorte que o que seria necessário era selecionar as normais, para se formarem com elas algumas escolas, onde se educassem convenientemente para. mais tarde, não produzirem criaturas anormais". 41

O mau exemplo era considerado muito pernicioso, já que induzia ao hábito de consumir bebidas alcoólicas.

40 E. de Moraes, "O Alcoolismo...", op. cit., p. 92.

41 B. Penna, "Sífilis e Alcoolismo", A Noite, 10/9/1928. 
"Ora, no lar, sendo o pai, o chefe de família, um dos entes que mais despertam e mantêm a atenção dos filhos e subordinados, e aquele sobre o qual as faculdades de observação destes mais se fixam ou aplicam, é, também e muito naturalmente, pela dele que procuram eles pautar suas condutas; e, nestas condições, se o exemplo que encontram é de um bebedor, de um desmoralizado, que aí implanta a miséria, a corrupção, a mendicidade, a prostituição e a vagabundagem, só lhes resta uma das soluções: extinguirem-se precocemente pela decadência física adquirida pela hereditariedade, ou terminarem seus dias no fundo das masmorras, como criminosos ou ébrios; ou finalmente, povoarem os manicômios, como degenerados". 42

Esta declaração descreve todos os horrores a que estavam condicionados aqueles que não se submetiam, não se normalizavam pelos padrões burgueses: eram estigmatizados e classificados, castigados e internados para que se tratassem e se curassem. Mas havia aqueles bêbados considerados incuráveis, os quais recebiam a denominação de degenerados — também conhecidos como seres humanos dotados de "baixos instintos" - e que se definiam por não mais se sensibilizarem com os apelos à ordem e à temperança: não se medicavam e não tinham mais salvação.

\section{III}

Os costumes populares - seu modo de vida e seu imaginário - causavam forte impacto nas classes dominantes. No Rio de Janeiro, lugares de freqüência híbrida, como a Lapa e o Centro, por exemplo, ganharam fama exatamente por possibilitar essa convivência próxima. O fascínio é recíproco e abrange todas as classes sociais. Parece-me evidente, porém, que a pressão sobre os hábitos cotidianos dos setores populares traz consigo uma concepção negativista a respeito deles. A negação era entendida em oposição aos conceitos burgueses vigentes na nova ordem. As famílias das classes pobres, ainda não adaptadas ao novo paradigma, mantinham seus hábitos e rituais costumeiros; sua educação nada tinha em comum com o que agora lhes era exigido.

Mesmo a ação feminina na cultura das classes populares sugere-me algumas diferenças em relação à mulher burguesa. A principal parece ser a necessidade de trabalhar para completar o orçamento familiar, tornando a função masculina de "chefe de família" um pouco mais difícil de ser assimilada. Ao mesmo tempo, também, se a mulher burguesa era idealizada como

42 Cunha Cruz, O Problema do..., op. cit, pp. 15-6. 
a guardiã da moral familiar e da ética do trabalho, distanciando-se cada vez mais do prazer - tido como "vulgar" - , as mulheres pobres buscavam, nos mesmos espaços que os homens, o prazer que conheciam de perto, e que agora era qualificado de promiscuidade.

As tarefas domésticas, em todos os níveis sociais, eram tipicamente femininas, e o homem quase não participava delas. Mas, a diferença assinalada anteriormente torna-se mais interessante porque parte da constatação de que, no espaço público, homens e mulheres partilhavam de forma mais ou menos comum os balcões e mesas de bares; bebiam juntos a aguardente ou a cerveja; e traziam a sua sensualidade à flor da pele.

Retomando, agora, a charge com que iniciamos este texto, constatamos uma pesada carga ideológica nos seus traços. Essa reunião familiar em um domingo de inverno foi exposta sob os tenebrosos estigmas do vício, da promiscuidade e da perversão. A senhora idosa assemelha-se às conhecidas imagens de bruxas; o aspecto sombrio do homem de terno, ao encher o copo do menino, acentua-se. Até a ganância do proprietário exacerba-se, tornando visíveis os anéis na sua mão; e a mãe, com a criança no colo, parece fazer parte de algum ritual maligno.

Todo o edifício de saberes esquadrinhadores e de disciplinas elucidativas construído pelas sociedades capitalistas ocidentais marca presença neste trabalho do cartunista Seth. O sentido que ele empresta a essas "alegrias de domingo" se aproxima muito da idéia de "depravação de costumes" 43 que apavorava Belisário Penna. Com relação ao alcoolismo, o que vemos na charge é a plastificação do preconceito burguês contra a cultura popular, contra os prazeres compartilhados. É um exemplo de propaganda ideológica capaz de desestruturar o arcabouço das antigas representações e significados que cada símbolo colocado no desenho possuía.

O engendramento de uma "doença alcoolismo" não é fruto dos "assombrosos avanços da ciência" 44 como queria Evaristo de Moraes, mas deriva da construção de uma racionalidade do trabalho gerada a partir de uma mentalidade argentária, preocupada com o lucro, com a produção, com a "utilitarização" das relações pessoais; pois, de outra forma, não haveria capitalismo. Nem progresso. Os estudos acerca da "medicalização" da sociedade burguesa vêm, ao longo dos últimos dez anos, trazendo cada vez mais luz sobre as relações de poder estabelecidas nesse contexto. Mas, ainda

43 B. Penna, O Demônio da Humanidade..., op. cit., p. 9.

44 E. de Moraes, "O Alcoolismo...", op. cit, p. 96. 
me parece necessário investigar o conceito de doença e sua implicação nas representações sociais como um todo.

O trabalho e a família constituem-se, apenas, em dois amplos vestígios da atuação dos ideólogos da nova ordem. Penetrando nessas abstrações descobrimos um mundo real, feito de gente com carne, osso e sangue nas veias, cujas relações, poucas vezes, seguem os modelos ideais. A matéria de trabalho do historiador está aí, nesse mundo real; é no cotidiano das relações pessoais que se travam as verdadeiras batalhas pelo poder. Só aí podemos encontrar vencedores ou vencidos.

\section{RESUMO}

\section{Alcoolismo: Algumas Reflexões acerca do Imaginário de uma Doença}

Neste artigo pretendo apresentar, de uma forma panorâmica, as reações apresentadas pela sociedade burguesa capitalista à classificação dada ao uso/abuso das bebidas alcoólicas como doença, ocorrida na metade do século passado. Utilizando principalmente fontes primárias, o artigo visa resgatar a história da "doentificação" de um costume popular, a partir da mudança dos padrões sociais, políticos e econômicos estabelecidos desde o fim do século XVIII. Ao centrar o enfoque no Brasil tenciono analisar, também, a influência que a medicina - e os médicos, em especial - teve na consolidação dessa nova ordem em nosso País. Evidenciando-se como uma incursão generalizante ao tema, o artigo busca relacionar atitudes e aspectos relevantes em outras sociedades, com os movimentos estabelecidos no Brasil, no sentido de coibir o consumo de bebidas alcoólicas, com destaque para a aguardente - conhecida popularmente como "parati". Este ensaio está balizado cronologicamente entre a metade do século passado e a segunda década do século atual tendo, todavia, ampliado algumas observações para além desse período.

\section{ABSTRACT \\ Alcoholism: Some Thoughts on the social Imagery of a Disease}

In this article, I present an overview of bourgeois capitalist society's reactions to the classification of the use/abuse of alcoholic beverages as a disease, a change that occurred in the mid-nineteenth century. Relying main- 
ly on primary sources, I endeavor to recapture this history of the process by which a popular costume became labeled as a disease, based on changes in the social, political, and economic patterns that had prevailed since the late eighteenth century. In focusing on Brazil, I also intend to analyze how medicine - and doctors in particular - wielded an influence in the consolidation of this new attitude here. As a broad exploration of the topic, the article seeks to relate relevant attitudes and aspects from other societies to the movements that gained ground in Brazil and that worked to deter the consumption of alcoholic beverages, especially cheap hard liquor [aguardente] - known popularly as parati. The essay covers the period from the mid-nineteenth century to the second decade of the twentieth, but extends some observations beyond these dates.

\section{RESUME \\ L'Alcoolisme: Quelques Réflexions au sujet de l'imaginaire lié à une maladie}

Cet article a pour but de présenter un panorama des réactions de la société bourgeoise capitaliste lorsque, vers la moitié du siècle dernier, l'usage et l'abus de l'alcool furent pour la première fois classés comme maladie. Basé essentiellement sur des sources primaires, il a pour but de révéler l'histoire de la pathologisation d'une coutume populaire, pathologisation survenue à partir de changements affectant les modèles sociaux, politiques et économiques établis dès la fin du XVIIIème siècle. En mettant en évidence le cas brésilien, l'auteur se propose avant tout d'analyser l'influence exercée par la médecine - et les médecins en général - sur la consolidation de ce nouvel ordre dans le pays. L'article constituant une incursion généralisante dans le thème en question, l'auteur s'efforce d'établir un lien entre les attitudes ou les aspects importants sous lesquels ce même thème se présente dans d'autres sociétés et les actions menées au Brésil dans le but de réprimer la consommation de boissons alcooliques, parmi lesquelles l'eau de vie plus connue sous le nom de "parati" — occupe une place de choix. Cet essai concerne la période située entre la moitié du siècle dernier et la seconde décennie de notre siècle. Il fait toutefois quelques observations au delà de cette période. 
